\title{
VARIAÇÃO TEMPORAL DO FITOPLÂNCTON NO CANAL ESTUARINO DE SANTOS (SP)
}

\author{
MASUDA, L. S. M. ${ }^{*} ;$ MOSER, G. A. $0 .{ }^{2} \&$ BARRERA-ALBA, J. J. ${ }^{3}$ \\ 1 - Instituto de Microbiologia, Laboratório de Biogeoquímica, Universidade Federal do Rio de Janeiro; \\ 2 - Faculdade de Oceanografia, Departamento de Oceanografia Biológica, Universidade Estadual do \\ Rio de Janeiro; \\ 3 - Instituto de Biologia, Departamento de Biologia Marinha, Universidade Federal do Rio de Janeiro. \\ * Corresponding author: shizuemm@yahoo.com.br
}

\begin{abstract}
Masuda, L. S. M.; Moser, G. A. O. \& Barrera-Alba, J. J. 2011. Temporal variation of phytoplankton in the estuarine channel of Santos (SP). Braz. J. Aquat. Sci. Technol., 15(1): 79 - 93. ISSN 1808-7035. An increase in abundance of potentially toxic dinoflagellates in the Santos channel, located in a highly urbanized and eutrophic estuarine complex, was reported in the literature. Prediction of such occurences is essential, but phytoplankton community structure in dynamic estuarine systems are difficult to analyze. In the present work, we attempted to discuss microphytoplanktonic community in relation to physical variables looking for shifts in composition, in time scales of 25 hours. To achieve our goal two surveys were performed on anchored stations during 25 hours (two complete tidal cicles) in the Santos channel, during November 2005 and March/April 2006. Diatom community enhanced in periods of lower current velocity (tide peaks) during dry season, probably due to lower stratification after tidal runs and light availability, while dinoflagellates enhanced after rainfall events, probably due to a higher haline stratification and an increase in dissolved nutrients. The occurrence in high density of Pseudo-nitzschia "seriata" and Prorocentrum minimum reinforces the necessity of a constant monitoring program in the region.
\end{abstract}

Keywords: Prorocentrum minium, Pseudo-nitzschia "seriata", dissolved nutrients, tides

\section{INTRODUÇÃO}

A distribuição da comunidade fitoplanctônica na coluna de água pode variar devido a processos físicos (ondas, correntes e marés), químicos (nutrientes) e biológicos (herbivoria, competição e migração) (Brunet \& Lizon 2003, Thompson et al. 2008). Em um dado ambiente a composição taxonômica do fitoplâncton é uma manifestação das estratégias ecológicas adaptativas das espécies e de seus modos de nutrição (e.g. autotrofia, distintas formas de mixotrofia), função direta de seu ambiente físico e químico (Margalef, 1997). Em estuários, os gradientes de salinidade, assim como as rápidas modificações nas marés, mistura vertical, nutrientes e turbidez condicionam as variações na comunidade fitoplanctônica (Baek et al., 2008). A identificação das condições ambientais capazes de conduzir à dominância de um determinado grupo fitoplanctônico, potencialmente nocivo ou não, é importante para programas de monitoramento, especialmente em áreas costeiras impactadas antropicamente (Mafra-Junior et al., 2006).

Trabalhos realizados no Canal Estuarino de Santos, área do presente estudo, assim como nos canais de São Vicente e Bertioga, demonstraram que as variações na composição fitoplanctônica e na produtividade primária são fortemente influenciadas pelas variações de maré e pela contribuição da descarga de água doce para o sistema (Gianesella et al., 2000; Gianesella-Galvão et al., 2005; Moser et al., 2005). Schmiegelow et al. (2008) em uma revisão sobre os produtores primários do Sistema Estuarino de Santos, apontam os nanoflagelados como o grupo predominante de organismos nesse sistema. De fato, nos estudos de Moser (2002) e Ancona (2007) a variação espaço-temporal do fitoplâncton em escala nictemeral e sazonal no Canal de Santos é discutida, e a predominância de nanoflagelados é destacada. No primeiro, variações na composição do fitoplâncton foram observadas em relação às marés e estabilidade da coluna de água, com dominância de diatomáceas (Skeletonema cf. costatum) em condições de maior estratificação; e nanoflagelados em períodos de maior mistura. Ancona (2007) observa o predomínio de nanoflagelados durante o ano todo, e o aumento na densidade de dinoflagelados nos períodos de menor pluviosidade.

Em uma revisão recente, compilando quase 100 anos (entre 1913 e 2002, e novos dados entre 2004 e 2006) de dados taxonômicos do microfitoplâncton, em águas costeiras do estado de São Paulo, Villac et al. (2008) apontam o Sistema Estuarino de Santos como uma das regiões mais estudadas, embora seja notável a descontinuidade temporal e espacial no conjunto de dados. Entre todas as espécies do fitoplâncton, as diatomáceas cêntricas e penadas em cadeia, como Asterionellopsis glacialis, Guinardia striata e espécies de Pseudo-nitzschia, são citadas em $51 \%$ a $80 \%$ dos estudos. 
Outro aspecto relevante do Sistema Estuarino de Santos são as contribuições antrópicas que levaram à maior eutrofização, devido à ocupação e uso do solo pela cidade, o pólo industrial de Cubatão e o maior porto da América Latina (Gasparro et al., 2008). A eutrofização pode causar modificações na estrutura e composição da comunidade fitoplanctônica, assim como na rede trófica (Pinckey et al., 2001). Os dados de diversidade fitoplanctônica das regiões costeiras do estado de São Paulo mostram um incremento na riqueza específica de dinoflagelados de $10 \%$ da comunidade fitoplanctônica entre 1913 e 2002, para mais de 30\% entre 2004 e 2006 (Villac et al., 2008).

Nesse contexto, o presente estudo tem por objetivo analisar a composição e a variação da comunidade fitoplanctônica na entrada do Canal Estuarino de Santos, nos períodos de novembro de 2005 e março/ abril de 2006; considerando as variações ambientais observadas em ciclos completos de maré, com amostragens horárias.

\section{MATERIAIS E MÉTODOS}

\section{Área de Estudo}

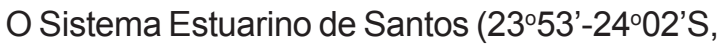
$46^{\circ} 27^{\prime}-46^{\circ} 15^{\prime} \mathrm{W}$ ) é composto por 3 canais estuarinos: Santos, São Vicente e Bertioga, interconectados na porção interna do sistema (Figura 1). O Canal Estuarino de Santos possui $14 \mathrm{~km}$ de extensão e profundidade média de 12 metros, com maré semi-diurna variando de 0,5 a 1,5 metros (Harari et al., 2008). A descarga média de água doce varia de $24 \mathrm{~m}^{3} / \mathrm{s}$ a $127 \mathrm{~m}^{3} / \mathrm{s}$, incluindo as descargas do rio Cubatão e da usina Henry Borden (SONDOTECNICA, 1977), essa última atualmente opera com carga mínima (Gasparro et al., 2008). O clima dessa região é tropical úmido, com índices pluviométricos variando entre $2000 \mathrm{~mm}$ e $4500 \mathrm{~mm}$ por ano. Sendo os maiores índices no verão, e os menores no inverno (DAEE, 2010).

\section{Estratégia amostral e análises laboratoriais}

Foram realizadas duas campanhas de amostragens de 25 horas cada uma, em uma estação fixa localizada na entrada do canal de Santos ( $23^{\circ} 59^{\prime} \mathrm{S}$, $46^{\circ} 18^{\prime}$ O) (Figura 1). A primeira campanha foi efetuada em 15 e 16 de novembro de 2005 (a partir daqui denominada como campanha de Novembro/2005); com amostragens iniciando às $12 \mathrm{~h} 30 \mathrm{~min}$ do dia 15 até $12 \mathrm{~h} 30 \mathrm{~min}$ do dia 16 de novembro. A segunda campanha foi realizada em 31 de março a 01 de abril de 2006 (a partir daqui denominada como campanha de Abril/2006), com amostragens iniciadas às 13h30min e terminando às $13 \mathrm{~h} 30 \mathrm{~min}$ do dia seguinte, dessa forma as amostragens foram realizadas em dois ciclos completos de maré.

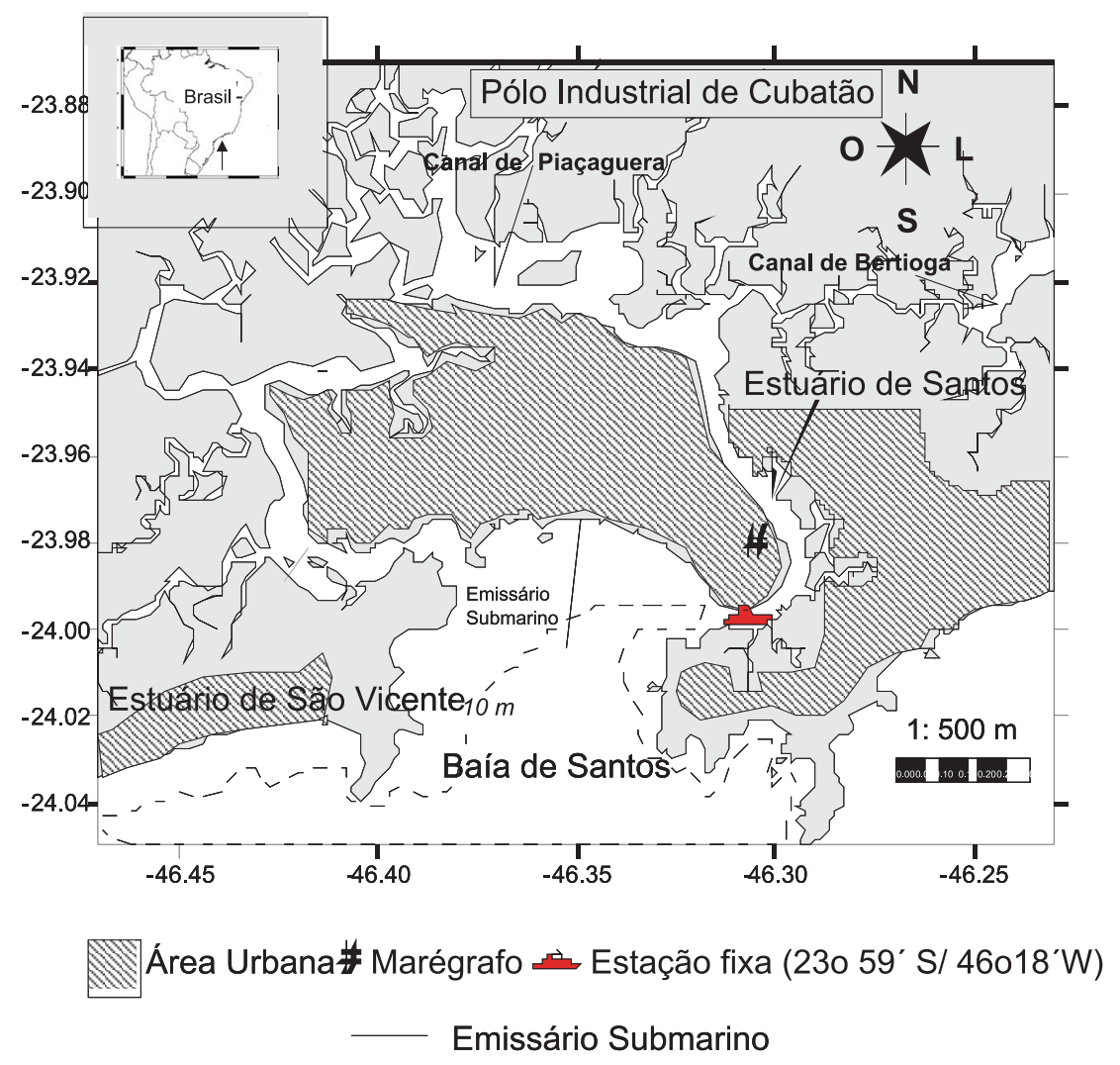

Figura 1 - Complexo estuarino de Santos, posicionamento da estação fixa. 
Perfis verticais de salinidade (S), temperatura (T), oxigênio dissolvido (OD) e porcentagem de saturação do oxigênio (\%OD) foram obtidos a cada hora, e a cada metro de profundidade, através do sensor multi-parâmetros (Yellowspring modelo 600LS). Em Novembro/2005 foram realizadas medidas desde a superfície até 5 a $7 \mathrm{~m}$ de profundidade, totalizando 183 medições; enquanto em Abril/2006 variou desde a superfície até 5 a $8 \mathrm{~m}$ de profundidade, totalizando 166 medições. A maioria das amostragens foram realizadas até $6 \mathrm{~m}$ de profundidade.

Para as análises dos nutrientes inorgânicos dissolvidos: silicato (Si), fosfato $\left(\mathrm{PO}_{4}\right)$, nitrito $\left(\mathrm{NO}_{2}\right)$ e nitrato $\left(\mathrm{NO}_{3}\right)$; séston; biomassa (clorofila-a) e composição da comunidade fitoplanctônica, foram coletadas amostras a cada duas horas com garrafas de Van Dorn em duas profundidades (superfície e a 1 metro do fundo).

A concentração de séston $\left(\mathrm{mg} \mathrm{L}^{-1}\right)$, dividida em material orgânico em suspensão (MOS) e material inorgânico em suspensão (MIS) foi obtida através da filtração de alíquotas de 250 a $500 \mathrm{ml}$, imediatamente após a amostragem, em filtros previamente combustionados e pesados (Millipore AP40, porosidade nominal de $0,7 \mu \mathrm{m}$ ). Esses foram mantidos ao abrigo da luz a $-20^{\circ} \mathrm{C}$ até o momento da análise pelo método gravimétrico descrito em APHA (1985).

Para a análise da concentração de clorofila-a $\left(\mathrm{mg} \mathrm{m}^{-3}\right)$ foram filtradas alíquotas de $500 \mathrm{~mL}$ em filtros de fibra de vidro (Millipore AP40, porosidade nominal de $0,7 \mu \mathrm{m}$ ), os filtros foram estocados imediatamente em nitrogênio líquido. Os pigmentos foram extraídos em acetona $90 \%$, e mantidos em freezer a $-20^{\circ} \mathrm{C}$ por 24 horas. As medidas de clorofila foram realizadas através do método espectrofotométrico tricromático descrito em Jeffrey \& Humphrey (1975). O filtrado foi recolhido e estocado a $-20^{\circ} \mathrm{C}$ em frascos de polietileno, previamente lavados com ácido clorídrico $10 \%$ e água destilada, para análises de nitrito, nitrato, fosfato e silicato. As amostras foram analisadas segundo os métodos espectrofotométricos descritos em Aminot \& Chaussepied (1983), para os nitrogenados, e Grasshoff et al. (1983), para fosfato e silicato.

A composição da comunidade fitoplanctônica foi analisada a partir de alíquotas de $100 \mathrm{~mL}$, preservadas em formaldeído neutralizado (concentração final de $0,4 \%$ ) e estocadas ao abrigo da luz em temperatura ambiente. Após homogeneização, sub amostras de 10 a $25 \mathrm{~mL}$ foram retiradas e dispostas em câmaras de sedimentação (Utermöhl, 1958). Após um mínimo de 12 horas de sedimentação, o fitoplâncton, foi identificado e contado em um microscópio invertido (marca Zeiss, modelo Axiovert) a uma magnificação de 400x. Pelo menos 200 células foram contadas para análise do microfitoplâncton e 400 células para o nanoplâncton (Lund et al. 1958), e identificadas ao menor nível taxonômico possível (espécie, gênero, família ou ordem) de acordo com os manuais de Cupp (1943), Balech (1988), Tomas (1997) e Tenenbaum et al. (2004). Alguns organismos foram identificados dentro de complexos, devido à sua difícil identificação em microscopia ótica, como: Pseudo-nitzschia "seriata" e Pseudo-nitzschia "delicatissima" (sensu Hasle 1965), e Cylindrotheca/Nitzschia. Foram calculados os índices de diversidade de Shannon (Washington, 1984) e equitabilidade (Magurran, 1988).

A precipitação diária foi obtida a partir dos registros do CEPTEC-INPE para a região (Climanálise, 2005; Climanálise, 2006) foram utilizados registros de 9 dias anteriores às amostragens mais o dia de coleta.

\section{Tratamento dos dados}

Para comparar as variáveis físicas, químicas e biológicas analisadas entre (i) as campanhas de Novembro/2005 e Abril/2006, (ii) entre as duas profundidades de coleta: superfície e fundo, e (iii) entre as marés enchente e vazante; foi realizado o teste não paramétrico de Mann-Whitney. Com o objetivo de extrair as tendências da variabilidade dos dados e reduzir a complexidade das relações existentes entre a comunidade fitoplanctônica e as variáveis ambientais foi aplicada Análise de Componentes Principais (ACP) ao conjunto de dados físicos, químicos e biológicos das campanhas de 2005 e 2006. Esses dados foram previamente normalizados por aplicação de logarítimo $[\log (x+1)]$ e padronizados. Todos os testes foram realizados com nível de significância de 0,05.

\section{RESULTADOS}

De uma forma geral, os resultados do teste de Mann-Whitney mostraram que as duas campanhas foram distintas em relação às variáveis físicas, químicas e biológicas (clorofila-a, composição e estrutura da comunidade) (Tabela 1), por isso a descrição dos resultados da composição e estrutura da comunidade é realizada para cada uma das campanhas separadamente.

\section{Variáveis ambientais}

$\mathrm{Na}$ campanha de novembro de 2005 a profundidade local variou de 7 a 11 metros. A coleta de maré enchente foi realizada nos horário de $12 \mathrm{~h} 30 \mathrm{~min}$ às $16 \mathrm{~h} 30 \mathrm{~min}$ e entre $02 \mathrm{~h} 30 \mathrm{~min}$ e $06 \mathrm{~h} 30 \mathrm{~min}$, como esperado foram observados os maiores valores de salinidade (Figura 2). Nessa campanha a precipitação média foi de $1,3 \mathrm{~mm} \mathrm{dia}^{-1}$, enquanto a média de temperatura foi $20^{\circ} \mathrm{C}$ e de salinidade 31,5 , valores relativamente altos e associados à menor precipitação (Tabela 1). 


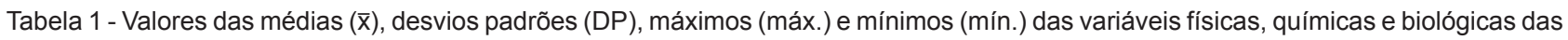
campanhas de Novembro/2005 e Abril/2006. Valores do resultado do teste de Mann-Whitney para as variáveis analisadas. Valores médios em destaque $\left(^{*}\right)$ são significativamente maiores (nível de significância $p<0.05$ ). MIS = material inorgânico dissolvido e MOS = material orgânico dissolvido. Os valores de densidade do Fitoplâncton total foram calculados sem considerar as densidades de nanoflagelados.

\begin{tabular}{|c|c|c|c|c|c|c|c|c|c|}
\hline \multirow{2}{*}{$\begin{array}{l}\text { Campanhas } \\
\text { Variáveis }\end{array}$} & \multicolumn{3}{|c|}{ Novembro/2005 } & \multirow[b]{2}{*}{ mín. } & \multicolumn{4}{|c|}{ Abril/2006 } & \multirow{2}{*}{$\begin{array}{c}\text { Teste Mann-Whitney } \\
\text { Valores de } p\end{array}$} \\
\hline & $\bar{x}$ & $\pm \mathrm{DP}$ & máx. & & $\bar{x}$ & $\pm \mathrm{DP}$ & máx. & mín. & \\
\hline Precipitação (mm dia $\left.{ }^{-1}\right)$ & 1.3 & 3.1 & 10.0 & 0.0 & $14.6^{*}$ & 22.7 & 80.0 & 0.0 & 0.0404 \\
\hline Temperatura $\left({ }^{\circ} \mathrm{C}\right)$ & 24.0 & 0.3 & 24.9 & 23.1 & $26.3^{*}$ & 0.2 & 26.8 & 25.7 & $<0.0001$ \\
\hline Salinidade & $31.5^{*}$ & 0.8 & 33.3 & 29.9 & 29.1 & 2.5 & 34.1 & 24.8 & $<0.0001$ \\
\hline Oxigênio dissolvido $\left(\mathrm{mg} \mathrm{L}^{-1}\right)$ & $6.6^{*}$ & 0.5 & 7.7 & 5.5 & 4.6 & 0.5 & 6.0 & 3.5 & $<0.0001$ \\
\hline \% Saturação D.O. & $94.0^{*}$ & 6.9 & 111.2 & 80.2 & 64.4 & 11.4 & 79.9 & 39.6 & $<0.0001$ \\
\hline Secchi (m) & $6.1^{*}$ & 1.4 & 9.5 & 4.1 & 4.3 & 1.3 & 6.8 & 2.7 & 0.0015 \\
\hline MIS $\left(\mathrm{mg} \mathrm{L}^{-1}\right)$ & $86.5^{*}$ & 47.5 & 250.0 & 58.0 & 59.2 & 27.7 & 146.8 & 11.7 & 0.0009 \\
\hline $\operatorname{MOS}\left(10^{3} \mathrm{mg} \mathrm{L}^{-1}\right)$ & 1.5 & 0.1 & 1.6 & 1.2 & 1.4 & 0.4 & 2.9 & 0.8 & 0.4260 \\
\hline Nitrito $\left(\mathrm{mg} \mathrm{L}^{-1}\right)$ & 0.4 & 0.2 & 0.9 & 0.1 & $2.6^{*}$ & 0.6 & 3.4 & 1.4 & $<0.0001$ \\
\hline Nitrato $\left(\mathrm{mg} \mathrm{L}^{-1}\right)$ & 1.5 & 0.9 & 3.8 & 0.1 & $5.2^{*}$ & 2.8 & 10.6 & 2.2 & $<0.0001$ \\
\hline Fosfato $\left(\mathrm{mg} \mathrm{L}^{-1}\right)$ & 0.1 & 0.1 & 0.2 & 0.0 & $0.3^{*}$ & 0.1 & 0.5 & 0.1 & $<0.0001$ \\
\hline Silicato $\left(\mathrm{mg} \mathrm{L}^{-1}\right)$ & 0.6 & 0.3 & 1.3 & 0.2 & $2.0^{*}$ & 0.4 & 2.6 & 1.3 & $<0.0001$ \\
\hline Clorofilara $\left(\mathrm{mg} \mathrm{m}^{-3}\right)$ & $5.3^{*}$ & 1.3 & 9.7 & 3.4 & 4.2 & 2.4 & 11.6 & 0.9 & 0.0211 \\
\hline Diatomácea cêntrica $\left(10^{5} \mathrm{cel} \mathrm{L}^{-1}\right)$ & $3,8^{*}$ & 3,8 & 15,8 & 0,6 & 1,2 & 0,9 & 3,3 & 0 & 0.0004 \\
\hline Diatomácea penada $\left(10^{5} \mathrm{cel} \mathrm{L}^{-1}\right)$ & $19,5^{*}$ & 13,5 & 41,3 & 4 & 1 & 0,8 & 2,4 & 0 & $<0.0001$ \\
\hline Dinoflagelados $\left(10^{5} \mathrm{cel} \mathrm{L}^{-1}\right)$ & 1,2 & 0,7 & 2,9 & 0,3 & $21^{*}$ & 60,7 & 288,6 & 0,2 & 0.0005 \\
\hline Fitoplâncton total $\left(10^{6} \mathrm{cel} \mathrm{L}^{-1}\right)$ & $3.4^{*}$ & 1.8 & 7.4 & 0.9 & 2.4 & 6.0 & 29.0 & 0.2 & $<0.0001$ \\
\hline Nanoflagelado $\left(10^{7}\right.$ cel L $\left.^{-1}\right)$ & $1.3^{*}$ & 0.7 & 3.5 & 0.4 & 0.9 & 0.5 & 2.3 & 0.3 & 0.0154 \\
\hline Riqueza & 18.0 & 4.3 & 27.0 & 8.0 & 18.4 & 6.5 & 29.0 & 4.0 & 0.3658 \\
\hline Equitabilidade & 0.5 & 0.1 & 0.7 & 0.4 & $0.8^{*}$ & 0.3 & 1.0 & 0.0 & $<0.0001$ \\
\hline Diversidade & 1.6 & 0.3 & 2.1 & 0.9 & $2.2^{*}$ & 1.0 & 3.2 & 0.0 & 0.0002 \\
\hline
\end{tabular}

Foram observadas as maiores médias das variáveis: OD $\left(6.6 \mathrm{mg} \mathrm{L}^{-1}\right), \% \mathrm{OD}(94 \%)$, MIS $(86,5 \mathrm{mg}$ $\left.\mathrm{L}^{-1}\right)$, clorofila-a $\left(5,3 \mathrm{mg} \mathrm{m}^{-3}\right)$ e profundidade da zona eufótica $(6,1 \mathrm{~m})$ (Tabela 1$)$.

Considerando a profundidade de coleta, superfície e fundo, as variáveis significativamente diferentes $(p<0,05)$ com as maiores médias foram: temperatura e fosfato em superfície; e salinidade junto ao fundo (Figura $3 a-c)$. Com relação à maré foram registrados maiores valores significativamente distintos $(p<0,05)$ de T, S e OD, na maré enchente; e $\mathrm{Si}, \mathrm{PO}_{4}, \mathrm{NO}_{2}$ e $\mathrm{NO}_{3}$; na maré vazante (Figura 4a-g). As variáveis Secchi, OD e \%OD, MIS, MOS, $\mathrm{NO}_{2}, \mathrm{NO}_{3}$, Si não apresentaram diferenças significativas com relação à profundidade. E as variáveis MIS e MOS não foram significativamente diferentes nas marés.

$\mathrm{Na}$ campanha de Abril/2006 a variação da profundidade na estação amostral foi de 6,6 a 8,3 metros. A maré enchente foi registrada entre $13 \mathrm{~h} 30 \mathrm{~min}$ e $17 \mathrm{~h} 30 \mathrm{~min}$ e entre $01 \mathrm{~h} 30 \mathrm{~min}$ e $05 \mathrm{~h} 30 \mathrm{~min}$, como esperado, foram observados os maiores valores de salinidade (Figura 2). A precipitação pluviométrica foi maior nessa campanha $\left(14,6 \mathrm{~mm} \mathrm{dia}^{-1}\right)$, associada aos maiores valores médios de temperatura $\left(26,3^{\circ} \mathrm{C}\right)$ e menores de salinidade $(29,1)$ (Tabela 1$)$.
Foram registradas as maiores médias de $\mathrm{NO}_{2}$ $\left(2,6 \mathrm{mg} \mathrm{L}^{-1}\right), \mathrm{NO}_{3}\left(5,2 \mathrm{mg} \mathrm{L}^{-1}\right), \mathrm{PO}_{4}\left(0,3 \mathrm{mg} \mathrm{L}^{-1}\right)$ e Si $\left(2,0 \mathrm{mg} \mathrm{L}^{-1}\right)$. Essas foram significativamente diferentes $(p<0,05)$ daquelas observadas na campanha de Novembro/2005 (Tabela 1).

Considerando a profundidade de coleta foram registrados maiores valores $(p<0,05)$ de T, S, MIS, MOS e clorofila-a nas amostras de fundo; e $\mathrm{PO}_{4}$ e Si nas amostras de superfície (Figura 5a-g). Quanto à maré, maiores valores $(p<0,05)$ de $T$ e $O D$ foram observados na enchente e $\mathrm{NO}_{2}$ na vazante (Figura 6ac). As demais variáveis não foram significativamente diferentes.

\section{Composição e estrutura da comunidade fitoplanctônica}

Campanha de Novembro 2005

Foram observadas nessa campanha, as maiores $(p<0,05)$ médias de densidade celular total de organismos $\left(3,4.106 \pm 1,8.106 \mathrm{cel} \mathrm{L}^{-1}\right)$. Os nanoflagelados, analisados à parte, foram predominantes, com densidade média de 1,3.107 $\pm 0,7.107 \mathrm{cel} \mathrm{L}^{-1}$ (Tabela 1). A contribuição relativa deste grupo variou de $65 \%$ a 95\% da abundância total dos organismos. 


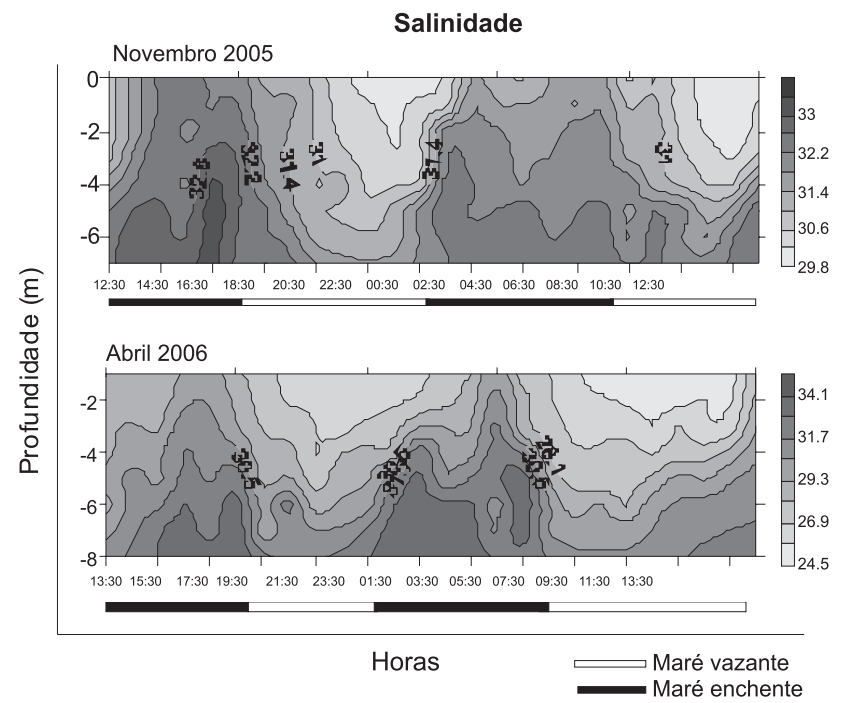

Figura 2 - Variação da salinidade na coluna de água ao longo de 25 horas nas campanhas de Novembro/2005 e Abril/2006.

Dentre os organismos nano- e microfitoplanctônicos identificados, as diatomáceas penadas (Bacillariales) foram dominantes, variando de 0,4 a $4,1.10^{6}$ cel L-1 (contribuição média de $73 \%$ ), seguida pelas diatomáceas cêntricas (Biddulphiales) variando de $5,8.10^{4}$ a $1,6.10^{6} \mathrm{cel} \mathrm{L}^{-1}(17 \%)$ e dinoflagelados (Dinophyceae) variando de 0,32 a $2,9.105 \mathrm{cel} \mathrm{L}^{-1}(6 \%)$. Os outros grupos como cocolitoforídeos (Prymnesiophyceae), cianobactérias (Cyanophycea), silicoflagelados (Dictyochophyceae) e flagelados maiores que 20 $\mu \mathrm{m}$, juntos, variaram de 0 a $1,6.10^{6} \mathrm{cel} \mathrm{L}^{-1}$ contribuindo com uma média de 4\% (Figura 7 ).
De uma forma geral as maiores densidades do fitoplâncton total foram observadas junto ao fundo, principalmente devido às maiores densidades das diatomáceas penadas e dinoflagelados (Figuras 3d,e; Figura 7). Observou-se uma relação direta das penadas, nanoflagelados e, conseqüentemente do fitoplâncton total com a maré, onde as maiores densidades $(p<0,05)$ foram registradas na enchente (Figura 4h,i,j). Em relação à profundidade não foram significativas as diferenças na densidade média de: fitoplâncton total, diatomáceas cêntricas e nanoflagelados. Considerando a maré não foram significativas as diferenças nas densidades de diatomáceas cêntricas e dinoflagelados.

Foram identificados 68 táxons (Tabela 2), sendo Pseudo-nitzschia "seriata" dominante na maioria dos horários, representando cerca de $60 \%$ do total da abundância relativa dos organismos identificados, seguida dos táxons: Pseudo-nitzschia "delicatissima” (9\%), Leptocylindrus minimus (4\%), Navicula spp (2,5\%), Trichodesmium sp. (2\%), Melosira sp. (2\%), Prorocentrum spp (2\%), Anabaena spp (1,8\%), Skeletonema cf. costatum (1\%) e Thalassiosira cf. punctigera (1\%).

Como conseqüência dessa alta dominância de Pseudo-nitzschia "seriata", menores valores de diversidade $(1,55 \pm 0,28)$ e equitabilidade $(0,54 \pm 0,09)$ foram observados nessa campanha (Tabela 1).

\section{Novembro 2005}
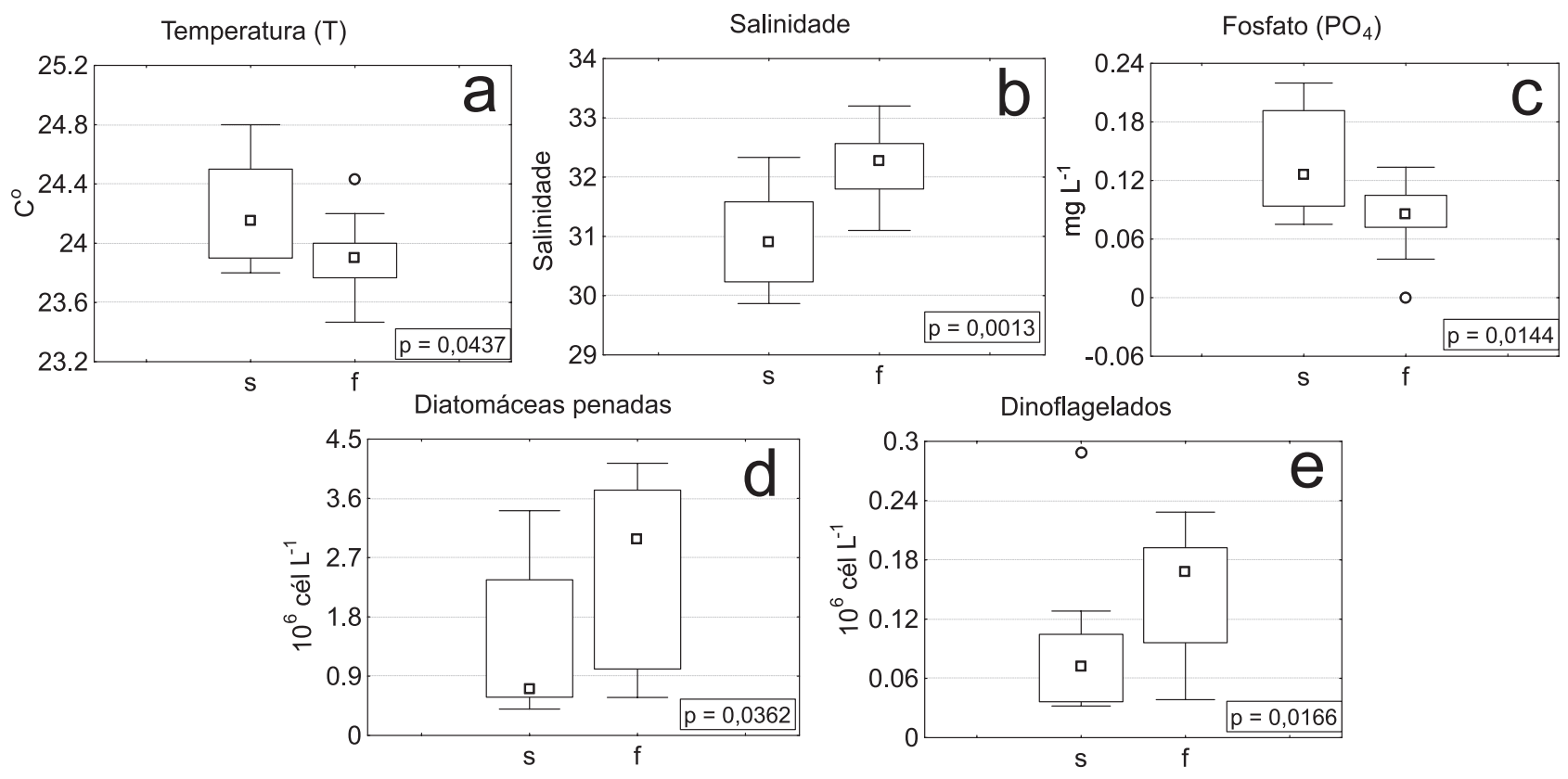

Figura 3 - Comparação das variáveis físicas, químicas e biológicas em amostras de superfície (s) e fundo (f) da campanha de Novembro/2005. 
Tabela 2 - Listagem dos organismos fitoplanctônicos identificados em dois ciclos completos de maré, nas campanhas de Novembro/2005 e Abril/2006. Enc. = maré enchente, Vaz. = maré vazante. Sistema de classificação segundo Tomas (1997).

\begin{tabular}{|c|c|c|c|c|c|c|c|c|c|}
\hline & \multirow[b]{2}{*}{ Maré } & \multicolumn{4}{|c|}{ Novembro/2005 } & \multicolumn{4}{|c|}{ Abril/2006 } \\
\hline & & Enc. & Vaz. & Enc. & Vaz. & Enc. & Vaz. & Enc. & Vaz. \\
\hline \multicolumn{10}{|l|}{$\begin{array}{l}\text { Ordem Nostocales } \\
\text { Família Nostocaceae }\end{array}$} \\
\hline $\begin{array}{c}\text { Anabaena spp } \\
\text { Ordem Oscillatoriales } \\
\text { Família Phormidiaceae }\end{array}$ & & $x$ & $x$ & $x$ & & $x$ & $x$ & & $x$ \\
\hline Trichodesmium spp & & $x$ & & & & & $x$ & & \\
\hline \multicolumn{10}{|l|}{ Classe Bacillariophyceae } \\
\hline $\begin{array}{l}\text { Familia Thalassiosiraceae } \\
\text { Cyclotella spp }\end{array}$ & & $x$ & $x$ & $x$ & & & $x$ & $x$ & \\
\hline Cyclotella sp1 & & $\hat{x}$ & $\hat{x}$ & $\lambda$ & & $\mathrm{x}$ & $\hat{x}$ & $\lambda$ & $\mathrm{x}$ \\
\hline Lauderia sp1 & & & $\mathrm{x}$ & $\mathrm{x}$ & $\mathrm{x}$ & & & & \\
\hline Skeletonema cf. costatum (Greville) Cleve & & $\mathrm{x}$ & & $\mathrm{x}$ & & $\mathrm{x}$ & $\mathrm{x}$ & & $\mathrm{x}$ \\
\hline Thalassiosira cf. punctigera (Castracane) Hasle & & $\mathrm{x}$ & $\mathrm{x}$ & $\mathrm{x}$ & $\mathrm{x}$ & $\mathrm{x}$ & $\mathrm{x}$ & $\mathrm{x}$ & $\mathrm{x}$ \\
\hline Thalassiosira cf. rotula Meunier & & $\mathrm{x}$ & & & & $\mathrm{x}$ & & & \\
\hline Thalassiosira sp1 & & & & & & $\mathrm{x}$ & & & $\mathrm{x}$ \\
\hline Thalassiosira sp2 & & & & & & & & & $\mathrm{x}$ \\
\hline Thalassiosira spp & & & & & & $\mathrm{x}$ & & & $\mathrm{x}$ \\
\hline \multicolumn{10}{|l|}{ Familia Melosiraceae } \\
\hline Melosira spp & & $\mathrm{x}$ & $\mathrm{x}$ & $\mathrm{x}$ & $\mathrm{x}$ & $\mathrm{x}$ & $\mathrm{x}$ & $\mathrm{x}$ & $\mathrm{x}$ \\
\hline Paralia sulcata (Ehrenberg) Cleve & & & & & & $\mathrm{x}$ & & $\mathrm{x}$ & \\
\hline Stephanopyxis turris (Greville \& Arnott) Ralfs & & & & & & & $\mathrm{x}$ & & \\
\hline \multicolumn{10}{|l|}{ Familia Leptocylindraceae } \\
\hline \multicolumn{10}{|l|}{ Familia Coscinodiscaceae } \\
\hline Coscinodiscus spp & & & $\mathrm{x}$ & $\mathrm{x}$ & $\mathrm{x}$ & $\mathrm{x}$ & $\mathrm{x}$ & $\mathrm{x}$ & $\mathrm{x}$ \\
\hline Coscinodiscus sp1 & & & & & $\mathrm{x}$ & $\mathrm{x}$ & $\mathrm{x}$ & & \\
\hline Coscinodiscus sp2 & & $\mathrm{x}$ & & & & & $\mathrm{x}$ & & \\
\hline \multicolumn{10}{|l|}{ Familia Heliopeotaceae } \\
\hline \multicolumn{10}{|l|}{ Familia Rhizosoleniaceae } \\
\hline Dactyliosolen fragilissimus (Bergon) Hasle & & $\mathrm{x}$ & & & & & & & \\
\hline Guinardia flaccida (Castracane) H. Peragallo & & & $\mathrm{x}$ & $\mathrm{x}$ & & $\mathrm{x}$ & & & \\
\hline Guinardia striata (Stolterfoth) Hasle & & $\mathrm{x}$ & $\mathrm{x}$ & $\mathrm{x}$ & $\mathrm{x}$ & & & & \\
\hline Guinardia sp1 & & & $x$ & $x$ & $\mathrm{x}$ & & & & \\
\hline $\begin{array}{l}\text { Rhizosolenia cf. hyalina Ostenfeld in Ostenfeld \& } \\
\text { Schmidt }\end{array}$ & & $x$ & & & $x$ & & & & \\
\hline Rhizosolenia hebetata Bailey & & $x$ & $x$ & & $x$ & & & & \\
\hline Rhizosolenia setigera Brightwell & & & & & & & & $\mathrm{x}$ & $\mathrm{x}$ \\
\hline Rhizosolenia cf. styliformis Brightwell & & & $\mathrm{x}$ & $\mathrm{x}$ & & & & & \\
\hline Rhizosolenia sp1 & & $\mathrm{x}$ & $\mathrm{x}$ & & $\mathrm{x}$ & & & & \\
\hline \multicolumn{10}{|l|}{ Família Hemiaulaceae } \\
\hline Cerataulina pelagica (Cleve) Hendey & & $x$ & $\mathrm{x}$ & & & $x$ & $\mathrm{x}$ & & \\
\hline Cerataulina sp. & & & & & & $\mathrm{x}$ & & & \\
\hline Eucampia zoodiacus Ehrenberg & & & $\mathrm{x}$ & & & & & & \\
\hline Eucampia sp. & & & & & & $\mathrm{x}$ & & & \\
\hline Hemiaulus sinensis Greville & & $\mathrm{x}$ & & & $\mathrm{x}$ & $\mathrm{x}$ & & & \\
\hline Hemiaulus sp. & & & & $\mathrm{x}$ & & & & & \\
\hline \multicolumn{10}{|l|}{ Família Cymatosiraceae } \\
\hline Cymatosira lorenziana Grunow & & & & & & & & & $\mathrm{x}$ \\
\hline Família Chaetocerotaceae & & & & & & & & & \\
\hline Chaetoceros affinis Lauder & & & & $\mathrm{x}$ & & & & & \\
\hline Chaetoceros Iorenzianus Grunow & & & $\mathrm{x}$ & & & & & & \\
\hline Chaetoceros spp & & $\mathrm{x}$ & $\mathrm{x}$ & & & $\mathrm{x}$ & & $\mathrm{x}$ & \\
\hline Chaetoceros sp1 & & & $\mathrm{x}$ & & & $x$ & & $\mathrm{x}$ & $\mathrm{x}$ \\
\hline Família Lithodesmiaceae & & & & & & & & & \\
\hline Ditylum brightwellii (T. West) Grunow & & $\mathrm{x}$ & $\mathrm{x}$ & $\mathrm{x}$ & $\mathrm{x}$ & & & & \\
\hline Ditylum sp1 & & & $\mathrm{x}$ & & & & & & \\
\hline Família Eupodiscaceae & & & & & & & & & \\
\hline Odontella mobiliensis (Bailey) Grunow & & $\mathrm{x}$ & & & & & & & \\
\hline Odontella sp1 & & & & & $\mathrm{x}$ & & & & \\
\hline Família Anaulaceae & & & & & & & & & \\
\hline Anaulus sp. & & $\mathrm{x}$ & & & & & $\mathrm{x}$ & $\mathrm{x}$ & \\
\hline
\end{tabular}

\section{Campanha de Abril 2006}

Os nanoflagelados formaram o grupo predominante com abundância relativa variando de 26 a $97 \%$ do total de organismos fitoplanctônicos.
Considerando os grupos taxonômicos identificados, os dinoflagelados foram predominantes devido à dominância de Prorocentrum minimum registrada prinicpalmente nos horários: 5h30min superfície, 7h30min fundo, 9h30min superfície e 13h30min fundo, 


\begin{tabular}{|c|c|c|c|c|c|c|c|c|}
\hline & \multicolumn{4}{|c|}{ Novembro/2005 } & \multicolumn{4}{|c|}{ Abril/2006 } \\
\hline Maré & Enc. & Vaz. & Enc. & Vaz. & Enc. & Vaz. & Enc. & Vaz. \\
\hline \multicolumn{9}{|l|}{ Classe Bacillariophyceae } \\
\hline \multicolumn{9}{|l|}{ Ordem Bacillariales } \\
\hline \multicolumn{9}{|l|}{ Família Fragilariaceae } \\
\hline Asterionellopsis glacialis (Castracane) Round & $\mathrm{x}$ & & $\mathrm{x}$ & & & & & \\
\hline \multicolumn{9}{|l|}{ Família Thalassionemataceae } \\
\hline Lioloma pacificum (Cupp) Hasle & & $x$ & & & & & & \\
\hline $\begin{array}{l}\text { Thalassionema cf. Bacillare (Heinden in Heinden \& } \\
\text { Kolbe) Kolbe }\end{array}$ & $\mathrm{x}$ & & & & & $x$ & & \\
\hline Thalassionema nitzschioides (Grunow) Mereschkowsky & & $x$ & $x$ & $x$ & $x$ & $x$ & $x$ & $x$ \\
\hline Thalassionema sp1 & & & & & $\mathrm{x}$ & $\mathrm{x}$ & & \\
\hline \multicolumn{9}{|l|}{ Família Naviculaceae } \\
\hline Meuniera membranacea (Cleve) P.C. Silva & $\mathrm{x}$ & & & $\mathrm{x}$ & & & & \\
\hline Navicula spp & $\mathrm{x}$ & $\mathrm{x}$ & $\mathrm{x}$ & $\mathrm{x}$ & $\mathrm{x}$ & $\mathrm{x}$ & $\mathrm{x}$ & $\mathrm{x}$ \\
\hline Navícula sp1. & $\mathrm{x}$ & $\mathrm{x}$ & & $\mathrm{x}$ & $\mathrm{x}$ & $\mathrm{x}$ & $\mathrm{x}$ & $\mathrm{x}$ \\
\hline Navícula sp2 & & & & & $\mathrm{x}$ & $\mathrm{x}$ & $\mathrm{x}$ & $\mathrm{x}$ \\
\hline Navícula sp3 & & & & & & & $x$ & \\
\hline Pleurosigma spp & & & & & $\mathrm{x}$ & $\mathrm{x}$ & & $\mathrm{x}$ \\
\hline \multicolumn{9}{|l|}{ Família Bacillariaceae } \\
\hline Complexo Cylindrotheca/Nitzschia & & & & $\mathrm{x}$ & $\mathrm{x}$ & & $\mathrm{x}$ & \\
\hline Fragilariopsis cf. doliolus (Wallich) Medlin \& Sims & $\mathrm{x}$ & $\mathrm{x}$ & $\mathrm{x}$ & $\mathrm{x}$ & $\mathrm{x}$ & & $\mathrm{x}$ & $\mathrm{x}$ \\
\hline Fragilariopsis sp. & & & & & & $\mathrm{x}$ & & \\
\hline Nitzschia spp & & $\mathrm{x}$ & & & & & & \\
\hline Pseudo-nitzschia "delicatissima" & $\mathrm{x}$ & $\mathrm{x}$ & $\mathrm{x}$ & $\mathrm{x}$ & & $\mathrm{x}$ & & \\
\hline Pseudo-nitzschia "seriata" & $\mathrm{x}$ & $\mathrm{x}$ & $\mathrm{x}$ & $\mathrm{x}$ & $\mathrm{x}$ & & & \\
\hline cf. Neodenticula & & $x$ & $\mathrm{x}$ & $\mathrm{x}$ & $x$ & $x$ & $x$ & $x$ \\
\hline \multicolumn{9}{|l|}{$\begin{array}{l}\text { Classe Haptophyceae } \\
\text { Ordem Coccosphaerales }\end{array}$} \\
\hline não identificados & $\mathrm{x}$ & $\mathrm{x}$ & $\mathrm{x}$ & $\mathrm{x}$ & $\mathrm{x}$ & $\mathrm{x}$ & $x$ & $\mathrm{x}$ \\
\hline Classe Dictyochophyceae & & & & & & & & \\
\hline Ordem Dictyochales & & & & & & & & \\
\hline Família Dictyochaceae & & & & & & & & \\
\hline Dictyocha fibula Ehrenberg & $\mathrm{x}$ & $\mathrm{x}$ & $\mathrm{x}$ & & & & & \\
\hline Dictyoha sp1 & & $x$ & & $x$ & & & $x$ & \\
\hline Classe Zoomastigophora & & & & & & & & \\
\hline Ordem Ebriida & & & & & & & & \\
\hline Família Ebriidae & & & & & & & & \\
\hline Ebria tripartita (Schumann) Lemmermann & & $\mathrm{x}$ & $\mathrm{x}$ & $\mathrm{x}$ & $\mathrm{x}$ & & & \\
\hline Classe Dinophyceae & & & & & & & & \\
\hline Ordem Prorocentrales & & & & & & & & \\
\hline Família Prorocentraceae & & & & & & & & \\
\hline Prorocentrum cf. balticum (Lohmann) Loeblich & & & $\mathrm{x}$ & & $\mathrm{x}$ & $\mathrm{x}$ & $\mathrm{x}$ & $\mathrm{x}$ \\
\hline Prorocentrum cf. compressum (Bailey) Abé ex Dodge & & & $\mathrm{x}$ & & & & $\mathrm{x}$ & $\mathrm{x}$ \\
\hline Prorocentrum gracile Schütt & $\mathrm{x}$ & & & & & & & $\mathrm{x}$ \\
\hline Prorocentrum cf. lima (Ehrenberg) Balech & $\mathrm{x}$ & & & & & & & $\mathrm{x}$ \\
\hline Prorocentrum micans Ehrenberg & & & & & & $\mathrm{x}$ & $\mathrm{x}$ & \\
\hline Prorocentrum minimum (Pavillard) Schiller & $\mathrm{x}$ & $\mathrm{x}$ & $\mathrm{x}$ & $\mathrm{x}$ & $\mathrm{x}$ & $\mathrm{x}$ & $x$ & $\mathrm{x}$ \\
\hline Prorocentrum cf. scutellum Schröder & & & & & & & $\mathrm{x}$ & \\
\hline Prorocentrum spp & $\mathrm{x}$ & $\mathrm{x}$ & $\mathrm{x}$ & $\mathrm{x}$ & $x$ & $x$ & $\mathrm{x}$ & $x$ \\
\hline Ordem Gymnodiniales & & & & & & & & \\
\hline Familia Gymnodiniaceae & & & & & & & & \\
\hline $\begin{array}{l}\text { Akashiwo cf. sanguinea (K. Hirasaka) G. Hansen \& } \varnothing \text {. } \\
\text { Moestrup }\end{array}$ & & & & & & & $\mathrm{x}$ & \\
\hline não identificados & $x$ & $x$ & $x$ & $x$ & $x$ & $x$ & $x$ & $x$ \\
\hline Ordem Gonyaulacales & & & & & & & & \\
\hline Família Ceratiaceae & & & & & & & & \\
\hline $\begin{array}{l}\text { Ceratium hircus Schröder) F.Gómez, D.Moreira \& P. } \\
\text { López-García }\end{array}$ & & & & & & & & $x$ \\
\hline Família Goniodomataceae & & & & & & & & \\
\hline Alexandrium cf. fraterculus (Balech) Balech & & $\mathrm{x}$ & & & & $\mathrm{x}$ & & \\
\hline Alexandrium sp. & & & & & $\mathrm{x}$ & $\mathrm{x}$ & $\mathrm{x}$ & \\
\hline Gambierdiscus cf. toxicus Adachi \& Fukuyo & & & & & & $\mathrm{x}$ & & \\
\hline Família Gonyaulacaceae & & & & & & & & \\
\hline Gonyaulax sp. & & & & & $x$ & & & \\
\hline Família Oxytoxaceae & & & & & & & & \\
\hline Oxytoxum crassum Schiller & & & & & & $\mathrm{x}$ & & \\
\hline Oxytoxum spp & & $\mathrm{x}$ & $\mathrm{x}$ & $\mathrm{x}$ & $\mathrm{x}$ & $\mathrm{x}$ & $\mathrm{x}$ & \\
\hline Família Calciodinellaceae & & & & & & & & \\
\hline Scrippsiella trochoidea (Stein) Loeblich III & $\mathrm{x}$ & $\mathrm{x}$ & $\mathrm{x}$ & & & & $x$ & $\mathrm{x}$ \\
\hline Família Protoperidiniaceae & & & & & & & & \\
\hline cf. Peridinium & $\mathrm{x}$ & & & $\mathrm{x}$ & & & & \\
\hline Protoperidinium spp & $\mathrm{x}$ & $\mathrm{x}$ & & $\mathrm{x}$ & $x$ & $x$ & $x$ & $x$ \\
\hline Protoperidinium cf. steinii (Jørgensen) Balech & & $\mathrm{x}$ & & & & & & \\
\hline
\end{tabular}




\section{Novembro 2005}
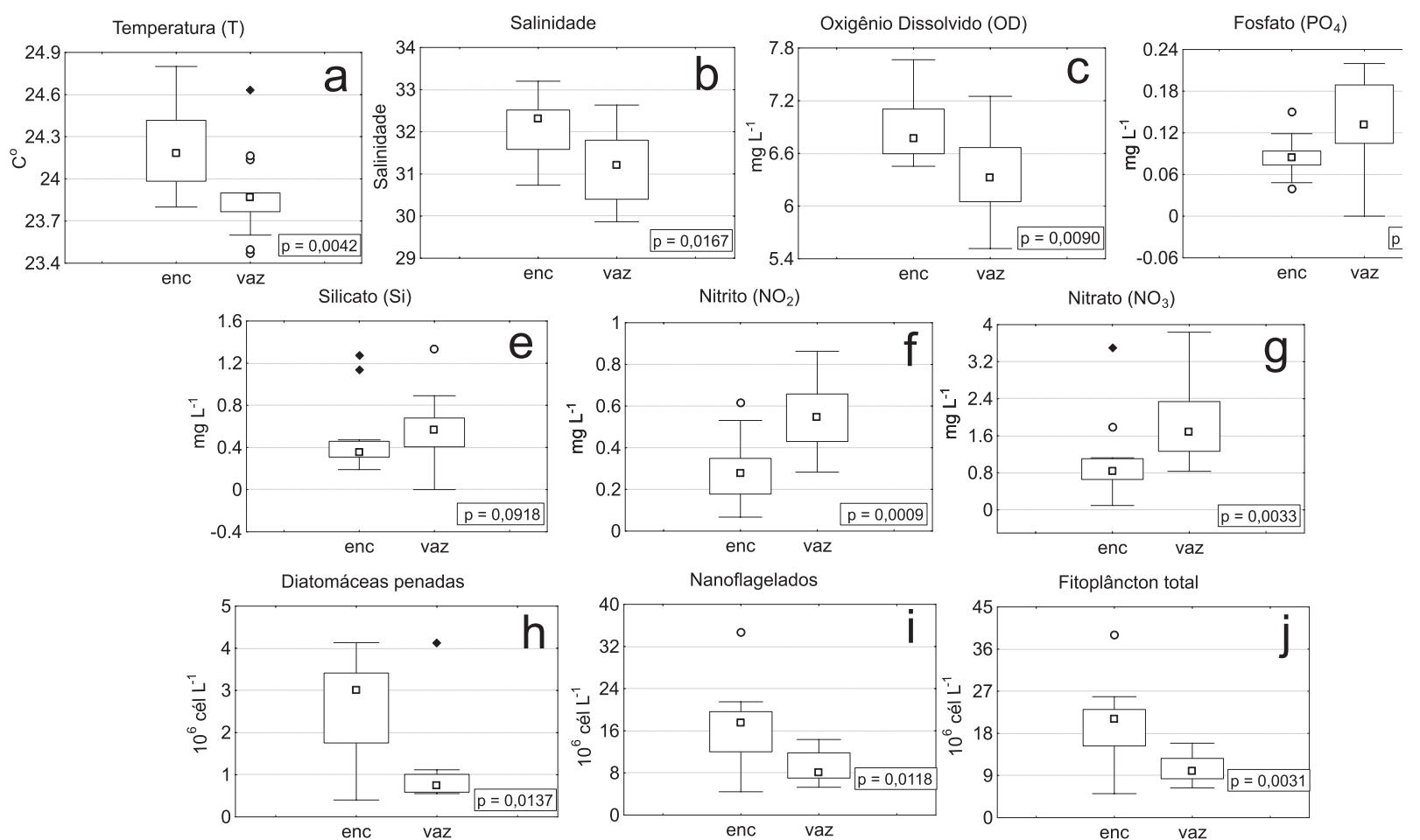

Figura 4 - Comparação das variáveis físicas, químicas e biológicas na maré enchente (enc) e vazante (vaz) da campanha de Novembro/2005.

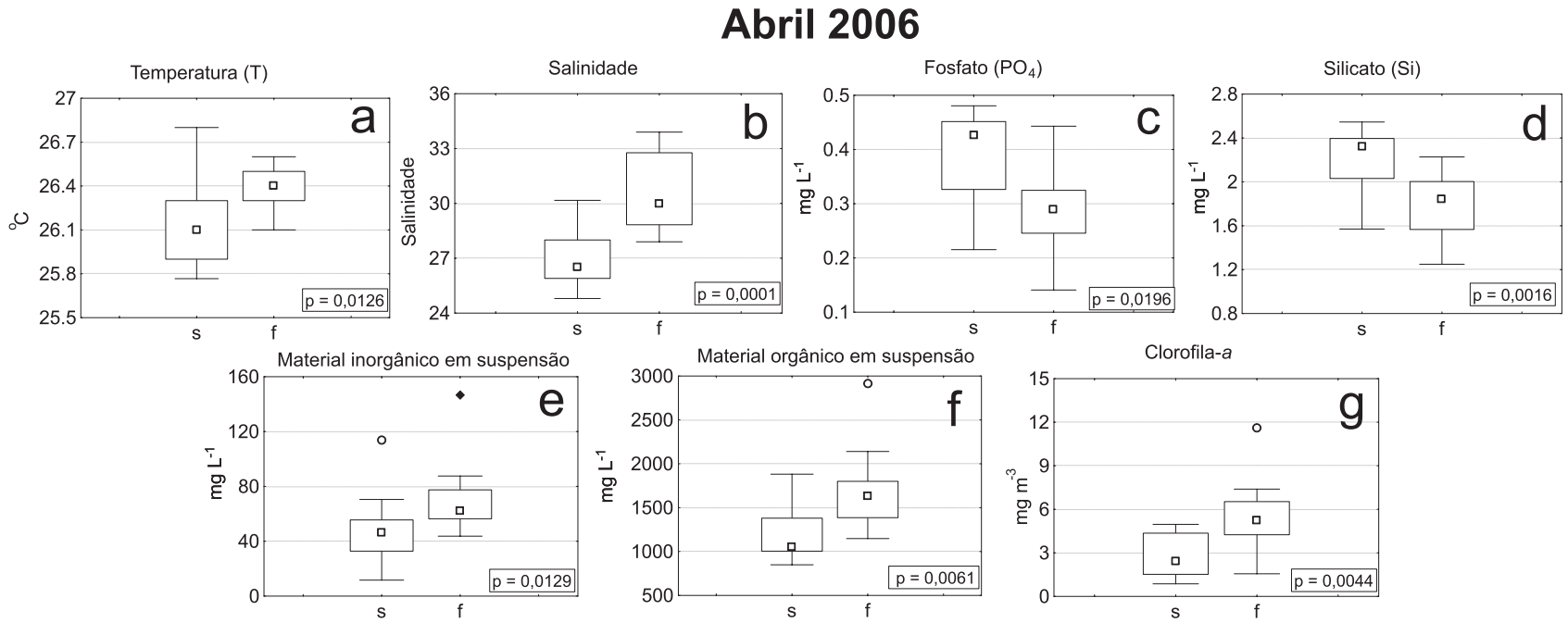

Figura 5 - Comparação das variáveis físicas, químicas e biológicas em superfície (s) e fundo (f) da campanha de Abril/2006.

com densidades de $4,1.10^{6} ; 2,9.10^{7}, 1,3.10^{7}$ e $2,6.10^{6}$ cel $\mathrm{L}^{-1}$, respectivamente. Esses valores não foram apresentados na Figura 8 para facilitar a visualização da distribuição dos grupos taxonômicos.

A densidade dos dinoflagelados variou de $2,0.10^{4}$ a $2,9.10^{7} \mathrm{cel} \mathrm{L}^{-1}$, contribuindo com uma média relativa de $54 \%$, seguida das diatomáceas penadas variando de 0 a $2,4.10^{5} \mathrm{cel} \mathrm{L}^{-1}(20 \%)$, e diatomáceas cêntricas variando de 0 a $3,7.10^{5} \mathrm{cel} \mathrm{L}^{-1}(19 \%)$; os ou- tros grupos como cocolitoforídeos, cianobactérias e silicoflagelados, juntos variaram de 0 a $2,4.10^{5} \mathrm{cel} \mathrm{L}^{-1}$, contribuindo com uma média de $8 \%$, o dobro do observado na campanha de Novembro/2005 (Figura 8). A variação da densidade do fitoplâncton total, nanoflagelados, diatomáceas cêntricas e penadas e dinoflagelados não foi significativamente distinta em relação à profundidade e às marés. 


\section{Abril 2006}
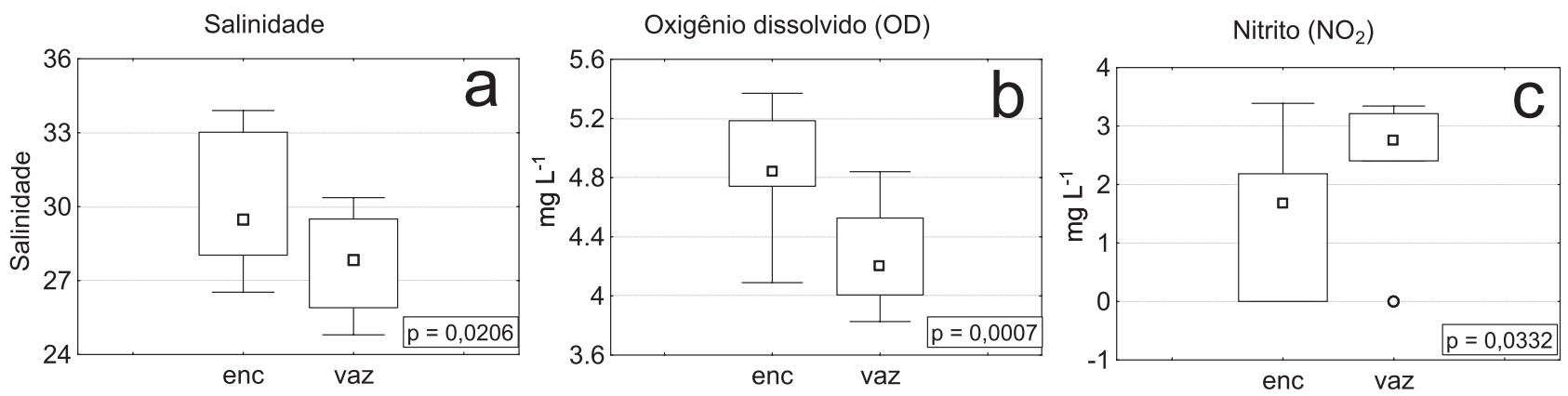

Figura 6 - Comparação das variáveis físicas e químicas na maré enchente (enc) e vazante (vaz) da campanha de Abril/2006.

Foram identificados 66 táxons (Tabela 2) dos quais o dinoflagelado Prorocentrum minimum representou $82 \%$ da abundância relativa total do fitoplâncton, devido aos eventos de dominância que ocorreram em alguns horários, seguido pelos táxons: Protoperidinium spp (3,2\%), Navicula spp (1,6\%), Prorocentrum spp $(1,5 \%)$, Thalassionema nitzschioides $(1,4 \%)$, Melosira sp. (0,9\%), Anabaena sp. $(0,9 \%)$ e Skeletonema cf. costatum $(0,7 \%)$.

A diversidade $(2.21 \pm 0.95)$ e equitabilidade $(0.75 \pm 0.29)$ foram maiores $(p<0,05)$ nessa campanha, pois a dominância de $P$. minimum ocorreu apenas e alguns horários (destacados acima) da amostragem, enquanto a dominância de Pseudo-nitzschia "seriata" ocorreu ao longo de toda campanha de Novembro/2005 (Tabela 1).

\section{Análise de Componentes Principais (ACP)}

A análise de componentes principais extraiu dois eixos com uma porcentagem acumulada de explicação de $56,5 \%$ da variância total dos dados, sendo o eixo 1 responsável por $44,6 \%$, o eixo 2 por $11,9 \%$.

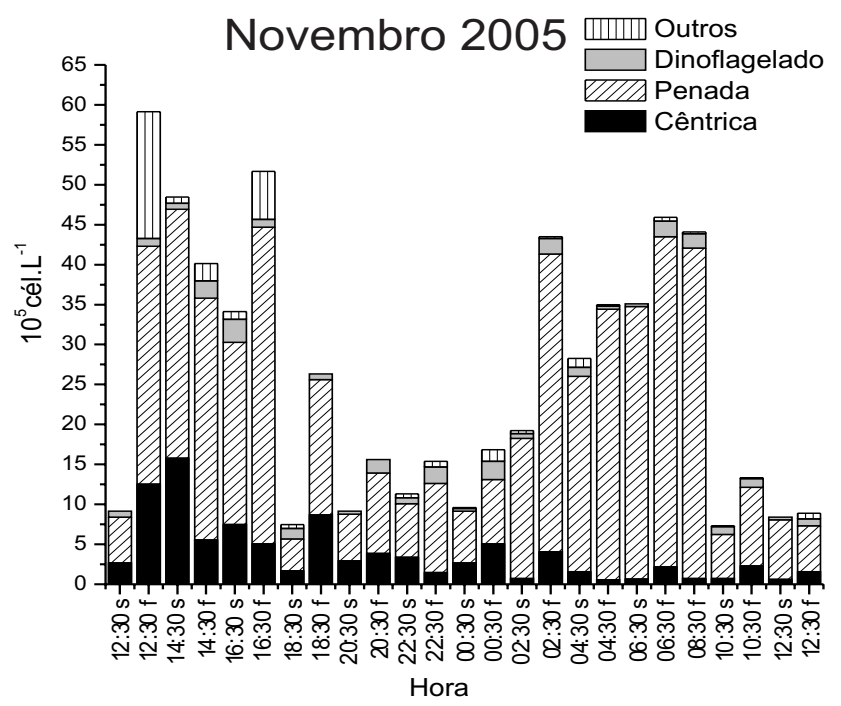

Figura 7 - Densidade $\left(10^{5}\right.$ cél.L-1 $)$ dos principais grupos taxonômicos identificados na campanha Novembro/2005. (s = superfície e $f=$ fundo).
No eixo 1 aparecem em sua porção positiva os vetores: S, OD, MIS, clorofila-a (Cla), NO2, diatomáceas cêntricas (cen), penadas (pen) e nanoflagelado (flag) na porção positiva; e, na porção negativa os vetores dos nutrientes e dinoflagelados. Este eixo refletiu a característica eutrófica do ambiente e a importância da variação temporal dos nutrientes, separando a campanha de abril de 2006, que apresentou maiores concentrações de nutrientes e aumento na densidade de dinoflagelados, na porção negativa do eixo, da campanha de novembro de 2005, na poção positiva do eixo (Figura 9).

No eixo 2 os vetores significativos foram: T, $\mathrm{Si}, \mathrm{MIS}, \mathrm{MOS}$, Cla, cen, dinoflagelados e flag na sua porção positiva, enquanto na porção negativa foram observados o OD e $\mathrm{NO}_{2}$. Este eixo caracteriza a influência da profundidade principalmente com relação ao séston (MOS e MIS) e Cla, separando as amostras coletadas próximas ao fundo com maiores concentrações de MIS, MOS e Cla na porção positiva do eixo, das amostras de superfície na porção negativa (Figura 9).

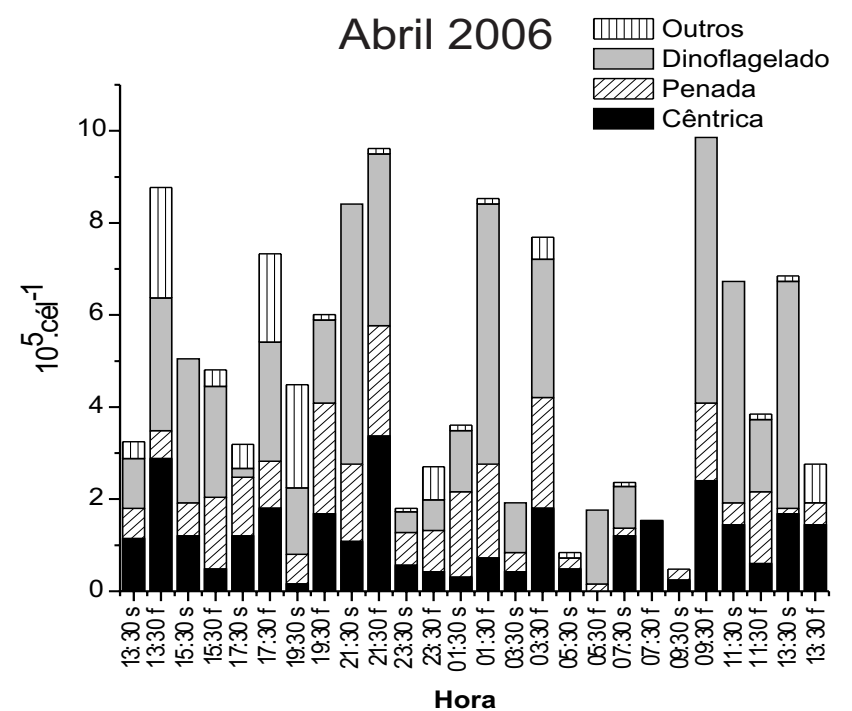

Figura 8 - Densidade $\left(10^{5}\right.$ cél.L-1 $\left.^{-1}\right)$ dos principais grupos taxonômicos identificados na campanha Abril/2006. ( $s=$ superfície e $f=$ fundo). 


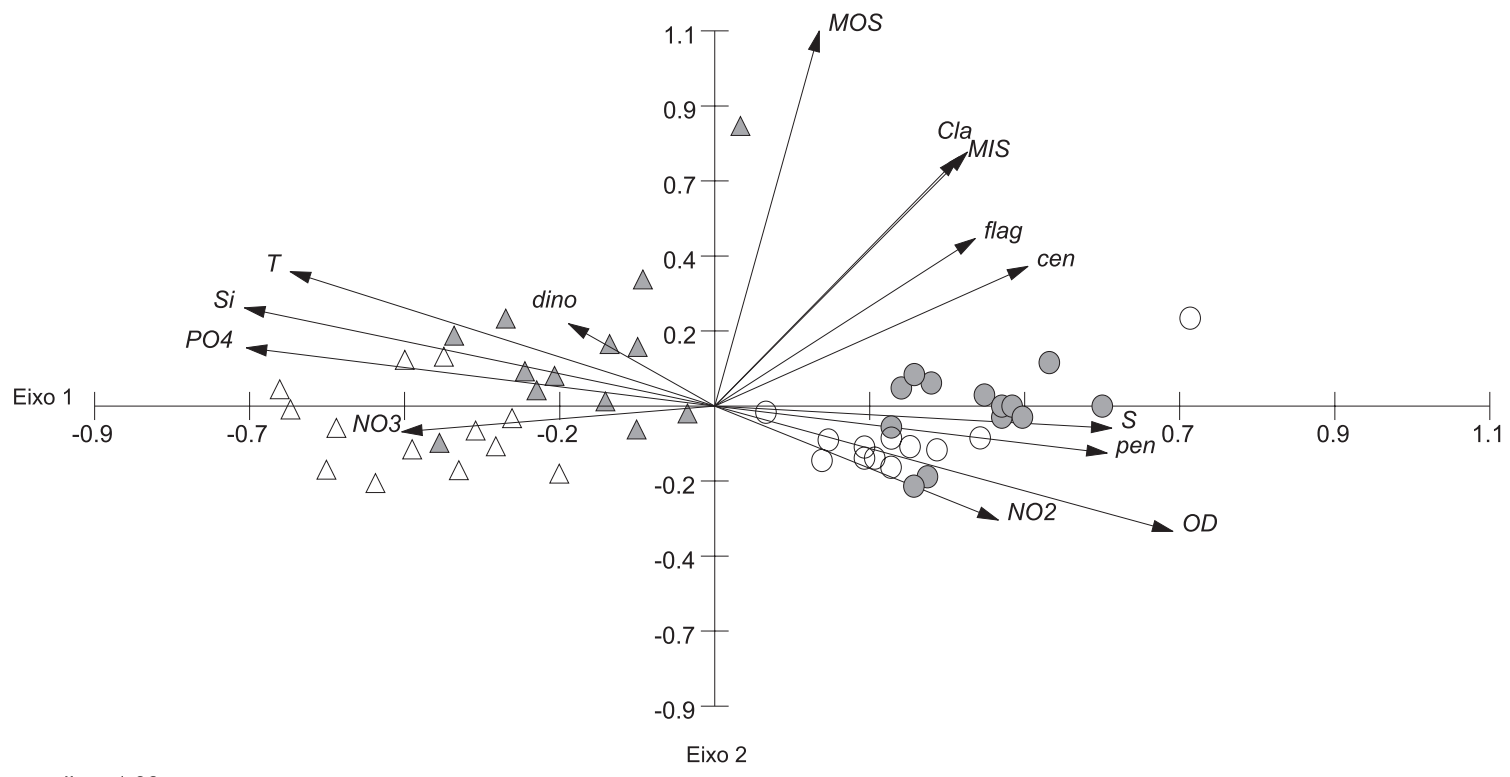

Vector scaling: 1.82

Figura 9 - Distribuição dos pontos amostrais no plano fatorial 1-2 da ACP dos dados físicos, químicos e biológicos. Os autovetores estão representados por setas $(T=$ temperatura; $S=$ salinidade; $O D=$ oxigênio dissolvido; $\mathrm{PO} 4$ = fosfato, $\mathrm{Si}=$ silicato; $\mathrm{MIS}=$ material inorgânico em suspensão; $\mathrm{MOS}$ = material orgânico em suspensão; $\mathrm{Cla}=$ clorofila-a; $\mathrm{NO}_{2}$ = nitrito; $\mathrm{NO}_{3}=$ nitrato; cen = diatomáceas cêntricas; pen = diatomáceas penadas; dino = dinoflagelados e flag $=$ nanoflagelado). Os símbolos representam os pontos amostrais (triângulos = Abril/2006; círculos = Novembro/2005; símbolos brancos = amostras de superfície; e símbolos cinza = amostras próximas ao fundo).

\section{DISCUSSÃO}

Em escala local, como no Canal Estuarino de Santos, fatores bottom-up como temperatura, salinidade, atenuação da luz, concentração de nutrientes, chuvas, descarga fluvial e mistura vertical podem influenciar na composição da comunidade fitoplanctônica (Adolf et al., 2006), uma vez que o plâncton responde rapidamente às flutuações físicas e químicas em curtas escalas temporais, e essa variabilidade imposta por esses fatores permite que muitas espécies coexistam (Scheffer et al., 2003). Dessa forma traçamos, a seguir, um panorana das fatores abióticos e da variação da estrutura e variação na composição da comunidade fitoplanctônica durante as campanhas amostrais no Canal Estuarino de Santos.

A área de estudo não apresenta estação seca bem definida, mas segundo a média pluviométrica mensal registrada pelo DAEE (2010) nos últimos 67 anos (1937 a 2004), os meses de janeiro, fevereiro, março e dezembro são os de maiores médias pluviométricas (400 $\mathrm{mm}$ por mês), e os meses de maio, junho, julho e agosto os de menores médias (150 mm por mês). Em novembro os índices pluviométricos para o mês ficam em torno de $250 \mathrm{~mm}$, com média diária de $8,3 \mathrm{~mm}$, enquanto em abril a média é de 10 $\mathrm{mm} \mathrm{dia}{ }^{-1}$. Na campanha de Novembro/2005 a média diária foi inferior aos valores comumente observado para esse mês, enquanto em Abril/2006 a média di- ária foi superior. A maior ocorrência de chuva nessa campanha também provocou menor profundidade e variação da zona eufótica, assim como maior variação na salinidade e consequentemente maior estratificação halina no sistema, comparado com a campanha de Novembro/2005.

Uma compilação de dados referentes às concentrações de nutrientes inorgânicos dissolvidos para a região do Canal Estuarino e Baía de Santos, considerando amostragens realizadas em 1978, 1998, 1999, 2000, 2001, 2004 e 2005 (Gianesella,1982; Pereira, 1985; Moser et al., 2004; Moser et al., 2005; Aguiar \& Braga, 2007; Ancona, 2007), mostrou as elevadas concentrações desses compostos inorgânicos, notadamente de nitrogênio amoniacal $(11,9$ $\mu \mathrm{M})$, nitrato $(9,3 \mu \mathrm{M})$ e fosfato $(4,3 \mu \mathrm{M})$, com maiores concentrações nos meses mais chuvosos de verão (Moser et al., 2005; Aguiar \& Braga, 2007; Ancona, 2007). No presente estudo, como esperado, a concentração de nutrientes inorgânicos foi maior durante a campanha de Abril/2006, correspondente ao final do verão, entretanto, as concentrações foram inferiores às médias descritas nos estudos anteriormente citados. Provavelmente esse aumento ocorreu devido ao maior índice pluviométrico nos dias antecedentes à coleta, dessa forma, ocorre aumento da drenagem continental e consequentemente do grau de eutrofização no sistema (Gianesella-Galvão, 1982; Moser et al., 2004; Moser et al., 2005). 
O predomínio de nanoflagelados na região costeira de São Paulo é um fato muito comum, como registrado por Aidar-Aragão \& Teixeira (1980), Gaeta et al. (1999), Gianesella et al. (2000) e na revisão realizada por Schimiegelow et al. (2008). As densidades observadas por esses autores são semelhantes àquelas obtidas nas duas campanhas amostrais realizadas nesse estudo.

A Análise de Componentes Principais (ACP) evidenciou as diferenças hidrográficas e as respostas da comunidade fitoplanctônica entre as duas campanhas amostrais. Na campanha de Novembro/2005 o aumento da densidade fitoplanctônica e das diatomáceas relacionado, principalmente, com a entrada das águas da Baía de Santos (maior salinidade). Apesar dos maiores valores de salinidades observados nessa campanha, a variação vertical deles foi significativamente diferente, provavelmente devido à circulação estuarina forçada por vento (Geyer, 1997; Harari et al., 2008). Outros autores também observaram a maior abundância relativa de diatomáceas em períodos de maior estratificação, como nos estofos de maré (Moser, 2002; Ancona, 2007). Além disso, a maior estratificação pode favorecer as diatomáceas em um ambiente limitado por luz, uma vez que as mantêm próximas à superfície (Demers et al., 1986). Nessa campanha a dominância de Pseudo-nitzschia torna-a responsável pela maior parte da variação da densidade celular. Segundo Villac et al. (2002) um dos principais fatores que controla a abundância e composição desse gênero é a salinidade.

A ocorrência de Pseudo-nitzschia "seriata" em regiões estuarinas próximas à área de estudo já foi registrada por outros autores (Gianesella et al., 2000; Moser, 2002; Ancona, 2007). Sua ocorrência também é comum no estado do Rio de Janeiro, com abundância relativa maior que $50 \%$, e em regiões mais ao sul do Brasil, com registro de ocorrência e de florações de espécies comuns ou tóxicas, em regiões estuarinas e costeiras, sempre associadas às variações hidrográficas (Villac \& Tenenbaum, 2001, Odebrecht et al., 2001).

Na campanha Abril/2006 a composição fitoplanctônica foi dominada por dinoflagelados, principalmente por Prorocentrum minimum na maioria das estações. As maiores densidades celulares dos organismos estão relacionadas com a maré (estofos e corridas de maré), assim como com o aumento da descarga de água doce no sistema e conseqüentemente maior estratificação halina, como observado por outros autores (Hallegraeff, 2003; Heil et al., 2005;). Diversas combinações de fatores ambientais, como altas concentrações de nutrientes, MOS e condições estuarinas podem estimular a floração de $P$. minimum (Witek \& Plinski, 2000; Glibert et al., 2001; Heil et al.,
2005). É bastante conhecida a ocorrência de florações de $P$. minimum sob altas temperaturas (Heil et al., 2005), após eventos de maiores fluxos de água doce (Glibert \& Magnien, 2004; Thompson et al., 2008), e em regiões costeiras e estuarinas eutrofizadas e estratificadas (Heil et al., 2005, Martínez-López et al., 2008).

A menor concentração de séston e o aumento da contribuição de MOS em períodos chuvosos, como na campanha de Abril/2006, também foi observada durante o projeto CIRSAN (circulação na Baia de Santos) (Ciotti, A. M.- comunicação pessoal). A contribuição estuarina de séston está relacionada ao aumento da pluviosidade local, e, portanto, é mais importante nos meses chuvosos de verão (Moser et al., 2005; DAEE, 2006). O transporte de material particulado é parcialmente dirigido pelos fluxos dos canais estuarinos de Santos e São Vicente. De acordo com Alfredini et al. (2008), em escalas temporais menores, como a do presente estudo, a ressuspensão do sedimento depositado também pode ser uma fonte importante de séston em marés de sizígia ou quando a mistura turbulenta é gerada por ventos mais fortes. Em marés de sizígia, ou em períodos de máxima velocidade da corrente de maré, o aumento da mistura turbulenta causa a ressuspensão de sedimentos de fundo, ricos em material inorgânico, enquanto que a diminuição dessa turbulência, dado ao aumento da estratificação halina, aumenta a contribuição de matéria orgânica, de origem fluvial (Ciotti, A. M.- comunicação pessoal), situação observada na campanha de Abril/2006. Considerando que o aumento na contribuição de MOS para o séston pode levar ao aumento do bacterioplâncton, e, além disso, o aumento da descarga fluvial aumenta a contribuição de ácidos húmicos no sistema, o dinoflagelado $P$. minimum, por suas características de mixotrofia (Heil et al., 2005) e possível utilização direta dos ácidos húmicos como fonte de energia (Carlsson et al., 1999), pode ter sido favorecido nessas condições observadas em Abril/2006.

De fato, os organismos fitoplanctônicos possuem capacidades fisiológicas diferentes, e suas respostas estão relacionadas à quantidade, qualidade e proporção dos nutrientes orgânicos e inorgânicos (Glibert et al., 2001, Thompson et al., 2008). De uma forma geral, o aumento da pluviosidade, do fluxo de água doce, e da estratificação halina no canal de Santos (Moser, 2002; Ancona, 2007), e diminuição do oxigênio dissolvido são potencialmente favoráveis aos dinoflagelados, principalmente pelo modo de nutrição, mixotrófico, observado em vários organismos desse grupo (Margalef, 1978b; Thompson et al., 2008).

Nas duas campanhas foi registrada a dominância de espécies formadoras de florações algais nocivas e/ou potencialmente produtoras de toxinas. A abundância relativa de cerca de $70 \%$ de Pseudo- 
-nitzschia "seriata" na campanha de Novembro/2005, acabou influenciando no índice de diversidade, onde os valores ficaram entre 1 e 2 . Esses valores de diversidade indicam número reduzido de espécies e dominância acentuada de uma ou duas espécies (Margalef, 1978a). Na campanha de Abril/2006, os valores de diversidade foram no geral entre 2 e 3 , com exceção da ocorrência de dominância de Prorocentrum minimum, onde a diversidade foi inferior a 1. Esses valores de diversidade indicam a presença de muitas espécies com uma estrutura estável e diversificada, sem que ocorra dominância nítida (Margalef, 1978a). A equitabilidade foi menor na campanha Novembro/2005, reflexo da abundância relativa de Pseudo-nitzschia.

Na campanha de Novembro/2005 foi registrada uma variação na densidade de Pseudo-nitzschia "seriata" de $10^{5}$ a $10^{6} \mathrm{cel} \mathrm{L}^{-1}$; e na campanha de Abril/2006 uma variação de $10^{3}$ a $10^{7} \mathrm{cel} \mathrm{L}^{-1}$ de Prorocentrum minimum. Esses valores de densidade encontrados no presente estudo, principalmente de Pseudo-nitzschia "seriata", são alarmantes, e caso houvesse produção de toxinas, as densidades de organismos observadas seriam suficientes para acumular toxinas em moluscos filtradores (Mafra-Junior et al., 2006). A produção de toxinas ASP por Pseudo-nitzschia australis, em densidades semelhantes ao observado para o complexo Pseudo-nitzschia "seriata" no presente estudo, causou a morte de pelicanos em Monte Rey (California) (Buck et al. 1992). Florações toxigênicas de Pseudo-nitzschia foram relacionadas ao aumento de matéria orgânica dissolvida no Canal de Santa Bárbara (EUA) (Anderson et al. 2009). Por outro lado a produção de toxina por Prorocentrum minimum ainda é discutida pelos autores (Glibert et al., 2001; Heil et al., 2005), entretanto cepas tóxicas (toxinas DSP) dessa espécie foram isoladas no Mediterrâneo francês por Grzebyk et al. (1997) em Heil, (2005). De qualquer maneira, a formação de florações algais que não produzem toxinas, pode causar outros danos, como depleção de oxigênio, mortalidade de organismos aquáticos por prejuízos físicos, ocasionando impactos econômicos, principalmente na pesca e turismo (Hallegraeff, 2003).

Vários autores sugerem que o aumento da eutrofização costeira favorece as florações algais nocivas (Glibert et al., 2001; Hallegraeff, 2003; Heil et al., 2005; Mafra-Junior et al., 2006). Os resultados obtidos mostram a dominância de espécies formadoras de florações algais nocivas nesse ambiente cada vez mais eutrofizado por diferentes fontes antrópicas e influenciado pela drenagem continental. Portanto, torna-se importante um programa de monitoramento com amostragens em pequenas escalas temporais (horárias em ciclos de maré completos) e em escala sazonal, para entender melhor a dinâmica do fitoplâncton frente às variações ambientais e evitar os possíveis efeitos negativos.

\section{CONCLUSÕES}

Na campanha de Novembro/2005 as diatomáceas penadas formaram o grupo taxonômico dominante, representadas principalmente por Pseudo-nitzschia "seriata", com cerca de $70 \%$ do total da abundância relativa fitoplanctônica. Um dos principais fatores responsáveis por essa alta abundância foi a salinidade, que apresentou maiores valores nessa campanha. Além disso, a contribuição dessas diatomáceas aumentou junto ao fundo, nos estofos de maré enchente, sugerindo a influência das águas da Baía de Santos.

Na campanha de Abril/2006, o grupo taxonômico predominante foi dos dinoflagelados, representados principalmente por Prorocentrum minimum, com $82 \%$ da abundância relativa total do fitoplâncton. A maior abundância dessa espécie está relacionada principalmente à alta concentração de MOS e nutrientes, associada aos maiores índices pluviométricos, maior drenagem continental e maior estratificação halina da coluna de água.

O aumento das diatomáceas nos períodos de estofo de maré na campanha de Novembro/2005 pode estar relacionado à menor velocidade de corrente, após um período de corrida de maré favorecendo a ressuspensão principalmente de diatomáceas penadas. Nesse ambiente estuarino, limitado por luz, a maior estratificação favorece esse grupo mantendo-o próximo à superfície. Por outro lado, na campanha de Abril/2006, o aumento da contribuição de água doce e da temperatura, pode favorecer o desenvolvimento de dinoflagelados.

Nas duas campanhas foram registradas dominâncias de espécies formadoras de florações algais nocivas e/ou potencialmente produtoras de toxinas. Esses resultados indicam a importância de um programa de monitoramento na região.

\section{REFERÊNCIAS}

Adolf, J.E.; Yeager, C. \& Miller, W.D. 2006. Environmental forcing of phytoplankton floral composition, biomass, and primary productivity in Chesapeake Bay, USA. • Estuar. Coast. Shelf Sci. 67: 108-122.

Aguiar, V.M.C. \& Braga, E.S. 2007. Seasonal and tidal variability of phosphorus along a salinity gradient in the heavily polluted estuarine system of Santos/ 
São Vicente - São Paulo, Brazil. Mar. Poll. Bull. 54(4): 464-488.

Aidar-Aragão, E. \& Teixeira, C. 1980. Produção primária e concentração de clorofila-a na costa brasileira (lat. $22^{\circ} 31^{\prime} \mathrm{S}$ - Long. $41^{\circ} 52^{\prime} \mathrm{W}$ a lat. $28^{\circ} 43^{\prime} \mathrm{S}-$ Long. $\left.47^{\circ} 57^{\prime} \mathrm{W}\right)$. Bolm. Inst. Oceanogr. 29 (2): 9-14.

Alfredini, P.; Arasaki, E. \& Amaral, R.F. 2008. Mean sea-level rise impacts on Santos Bay, Southeastern Brazil - physical modelling study. Environ. Monitor. Assess. 144: 377-387.

Aminot, A. \& Chaussepied, M. 1983. Manuel des analyses chimiques en milieu marin. Brest, C.N.E.X.O., 376p.

Ancona, C.M. 2007. Aspectos da variação espacial e temporal da biomassa e produção fitoplanctônica e parâmetros correlatos no estuário e baía de Santos. Dissertação de Mestrado. Instituto Oceanográfico da Universidade de São Paulo IOUSP. 229p.

Anderson, C.R.; Siegel, D.A.; Kudela, R.M. \& Brzezinski, M.A. 2009. Empirical models of toxigenic Pseudo-nitzschia blooms: Potential use as a remote detection tool in the Santa Barbara Channel. Harm. Alg. 8: 478-492.

APHA (AMERICAN PUBLIC HEALTH ASSOCIATION, inc.). 1985. Standard Methods for the Examination of Water and Wastewater. $16^{a}$ Edição, Washington, D.C.

Baek, S.H.; Shimode, S.; Han, M.S. \& Kikuchi, T. 2008. Growth of dinoflagellates, Ceratium furca and Ceratium fusus in Sagami Bay, Japan: The role of nutrients. Harm. Alg. 7: 729-739.

BALECH, E. 1988. Los dinoflagelados del Atlantico sudoccidental. Publ. Espec. Inst. Esp. Oceanogr. 1.

Brunet, C. \& Lizon, F. 2003. Tidal and diel periodicities of size fractionated phytoplankton pigment signatures at an onshore station on in the southeastern English Channel. Estuarine Coastal and Shelf Science. 56: 833-843.

Buck, K.R.; Uttal-Cookel, L.; Pilskaln, C.H.; Roelke, D.L.; Villac, M.C.; Fryxell, G.A.; Cifuentes, L. \& Chavez, F.P.1992. Autecology of the diatom Pseudonitzschia australis, a domoic acid producer, from Monterey Bay, California. Mar. Ecol. Prog. Ser., 84: 293-302.

Carlsson, P.; Granéli, E. \& Segatto, A.Z. 1999. Cycling of biologically available nitrogen in riverine humic substances between marine bacteria, a heterotrophic nanoflagellate and a photosynthetic dinoflagellate. Aquat. Microb. Ecol. 18: 23-36.

CLIMANÁLISE. 2005. Boletim de monitoramento e análise climática. vol. 20, (1), (6), (8) e (12).
CLIMANÁLISE. 2006. Boletim de monitoramento e análise climática. Ano 3, n 1. (http://climanalise. cptec.inpe.br/ rclimanl/revista/ano3.shtml).

CUPP, E. E. 1943. Marine plankton diatom of the West coast of North America. Bull. Scripps Inst. Oceanogr. 6(1): 238 pp.

DAEE (Departamento de Água e Energia Elétrica) 2010. (www.daee.sp.gov.br).

Demers, S.; Legendre, L. \& Therriault, J.C. 1986. Phytoplankton responses to vertical tidal mixing. In: Bowman, J.; Yentsch, M. \& Peterson, W. T. (eds). Lecture Notes on Coastal and Estuarine Studies. Springer, Berlin. 1-40 pp.

Gaeta, S.A.; Susini, S.M.; Metzler, P.M.; Francos, M.S. \& Abe, D.S. 1999. Environmental forcing on biomass and primary productivity of coastal ecosystem in Ubatuba region, southern Brazil. Rev. Bras. Oceanogr. 47(1):11-27.

Gasparro, M.R.; Sousa, E.C.P.M.; Giordano, F. \& Argentino-Santos, R.C. 2008. Occupation history of the Santos estuary. In: Ramiro Neves, R.; Baretta, J. \& Mateus, M. (eds.). Perspectives on Integrated Coastal Zone Management in South America, IST Press, Lisboa. 603 p.

Geyer, W.R. 1997. Influence of Wind on Dynamics and Flushing of Shallow Estuaries. Estuar. Coast. Shelf Sci. 44: 713-722.

Gianesella-Galvão, S.M.F. 1982. Standing-stock and potential production of phytoplankton in the bay of Santos, Brazil. Bolm. Inst. Oceanogr. 31(2): 85- 94.

Gianesella, S.M.F.; Saldanha-Correa, F.M.P. \& Teixeira, C. 2000. Tidal effects on nutrients and phytoplankton distribution in Bertioga Channel, São Paulo, Brazil. Aquat. Ecos. Health \& Manag. 3: $533-544$.

Gianesella-Galvão, S.M.F.; Saldanha-Correa, F.M.P.; Miranda, L.B.; Correa, M.A. \& Moser, G. A. O. 2005. Short-term variability and transport of nutrients and chlorophyll-a in Bertioga channel, São Paulo state, Brazil. Braz. J. Oceanogr. 53(3-4):99-114.

Glibert, P.M.; Magnien, R.; Lomas, M.W.; Alexander, J.; Fan, C.; Haramoto, E.; Trice, M. \& Kana T.M. 2001. Harmful Algal Blooms in the Chesapeake and Coastal Bays of Maryland, USA: Comparison of 1997, 1998, and 1999 Events. Estuaries 24(6A): 875-883.

Glibert, P.M. \& Magnien, R.E. 2004. Harmful algal blooms in the Chesapeake Bay, USA: Common species, relationships to nutrient loading, management approaches, successes and challenges. In: Hall, S.; S. Etheridge; D. Anderson; J. Kleindinst; Z. Mingyuan \& Z. Yinglin (eds). Harmful Algae Management and Mitigation. 48-55 pp. 
Grasshoff, K.; Ehrhardt, M. \& Kremling, K. 1983. Methods of seawater analysis. 2th Edition. Basel, Verlag Chemie. $419 \mathrm{p}$.

Grzebyk, D.; Denardou, A.; Berland, B. \& Pouchus, Y.F. 1997. Evidence of a new toxin in the red-tide dinoflagellate Prorocentrum minimum. J. Plankton Res. 19: 1111-1124.

Hallegraeff, G. M. 2003. Harmful Algal Blooms: a global overview. In: Hallegraeff, G.M.; Anderson, D.M. \& Cembella, A.D. (eds.). Manual on Harmful Marine Microalgae - Monographs on oceanographic methodology 11. 2th Edition. Paris, UNESCO. 25-50 pp.

Harari, J.; França, C.A.S. \& Camargo, R. 2008. Climatology and Hydrography of Santos Estuary. In: Ramiro N.R.; Baretta, J. \& Mateus, M. (eds.) Perspectives on Integrated Coastal Zone Management in South America. IST Press, Lisboa. $603 \mathrm{p}$.

Hasle, G.R. 1965. Nitzschia and Fragilariopsis species studied in the light and electron microscopes. II. The group Pseudonitzschia. Skr. norske Vidensk Akad. I. Mat. Nat. KI. N.S., 18: 1-45.

Heil, C.A.; Glibert, P.M. \& Fan, C.L. 2005. Prorocentrum minimum (Pavillard) Schiller: a review of a harmful algal bloom species of growing worldwide importance. Harm. Alg. 4: 449-470.

Jeffrey, S.W. \& Humphrey, G.F. 1975. New spectrophotometric equations for determining chlorophylls a, b, c and c2 in higher plants, algae and natural phytoplankton. Biochem. Physiol. Planzen (BPP) Bol. 167:191-194.

Lund, J.W.G.; Kipling, C. \& Le Cren, E.D. 1958. The inverted microscope method of estimating algal numbers and the statistical basis of estimations by counting. Hydrobiologia. 2: 143-170.

Mafra-Junior, L.L.; Fernandes, L.F. \& Proença, L.A. De O. 2006. Harmful algae and toxins in Paranaguá Bay, Brazil: bases for monitoring. Braz. J. Oceanogr. 54: 107-121.

Magurran, A.E. Ecological diversity and its measurements. 1988. Princeton University Press, Princeton. $200 \mathrm{p}$.

Margalef, R. 1978 a. Diversity. In: SOURNIA, A (ed). Phytoplankton manual. United Kingdon. UNESCO. 251-260 pp.

Margalef R. 1978 b. Life-forms of phytoplankton as survival alternatives in an unstable environment. Oceanol. Acta. 1: 493509.

Margalef, R. 1997. Turbulence and marine life. Marrasé, C.; Saiz, E. \& Redondo, J.M. (eds.). Lectures on plankton and turbulence. Sci. Mar. 61 (1): 109-123.

Martínez-López, A.; Escobedo-Urías, D.C.; UlloaPérez, A.E. \& Aguirre, R. 2008. Dynamics of a
Prorocentrum minimum bloom along the northern coast of Sinaloa, Mexico. Cont. Shelf Res. 8: 1693-1701.

Moser, G.A.O. 2002. Aspectos da eutrofização no sistema estuarino de Santos: distribuição espaço temporal de biomassa e produtividade primária fitoplanctônica e transporte instantâneo de sal, clorofila-a, material em suspensão e nutrientes. Tese de Doutorado, Instituto Oceanográfico, Universidade de São Paulo.

Moser, G.A.O.; Sigaud-Kutner, T.C.S.; Cattena, C.O.; Gianesella, S.M.F.; Braga, E.S.; Schinke, K.P. \& Aidar, E. 2004. Algal growth potencial as an index of eutrophication degree in coastal areas under sewage disposal influence. Aquat. Ecos. Health \& Manag. 7(1): 115-126.

Moser, G.A.O.; Gianesella, S.M.F.; Barrera-Alba, J.J.; Bergamo, A.L.; Saldanha-Correa, F. M.P.; Miranda, L.B. \& Harari, J. 2005. Instantaneous transport of salt, nutrients, suspended matter and chlorophyll-a in the tropical estuarine system of Santos. Braz. J. Oceanogr. 53(3/4):115-127.

Odebrecht, C; Ferrario, M.E.; Ciotti, A.M.;Kitzmann, D.; Moreira, M.O.P. \& Hinz, F. 2001. The distribution of the diatom Pseudo-nitzchia off Southern Brazil and relashionships with oceanographic conditions. In: Hallegraeff, G.M.; Blackburn, S.I.; Bolch, C.J. \& Lewis, R.J. (eds). Harmful Algal Bloom 2000. Tasmania, Australia. 42-45 pp.

Pereira, N. 1985. Eutrofização do Sistema Estuarino e das Baías de santos e São Vicente (Estado de São Paulo, Brasil). Dissertação de Mestrado. Universidade de São Paulo, Faculdade de Saúde Pública. $157 \mathrm{p}$.

Pinckney, J., Paerl, H.; Tester, P. \& Richardson, T. 2001. The role of nutrient loading and eutrophication in estuarine ecology. Environ. Health Perspect., 109: 699-706.

Scheffer, M.; Rinaldi, S.; Huisman, J. \& Weissing, F. 2003. Why plankton communities have no equilibrium: solutions to the paradox. Hydrobiologia 491: 9-18.

Schmiegelow, J.M.M.; Gianesella, S.M.F.; Simonetti, C.; Saldanha-Correa, F.M.P.; Feoli, E.; Santos, J.A.P.; Santos, M.P.; Ribeiro, R.B. \& Sampaio, A.F.P. 2008. Primary Producers In Santos Estuarine System. In: Neves, R.; Baretta, J.; Mateus, M. (eds.) Perspectives on Integrated Coastal Zone Management in South America. 1th Press, Lisboa. 603p.

SONDOTECNICA, 1977. Comportamento hidráulico e sedimentológico do estuário santista. Ministério dos Transportes, Empresa de Portos do Brasil S. A., PETROBRAS e Instituto de Pesquisas Hidráulicas- INPH. 343 p. 
Tenenbaum, D.R.; Villac, M.C.; Viana, S.C.; Matos, M.; Hatherly, M.; Lima, I.V. \& Menezes, M. 2004. Phytoplankton Atlas, Sepetiba Bay, Brazil. Globallast Monography, Series 16. 132 p.

Thompson, P.A.; Bonham, P.I. \& Swadling, K.M. 2008. Phytoplankton blooms in the Huon Estuary Tasmania: top-down or bottom-up control? J. Plankton Res. 30(7): 735-753.

Tomas C.R. (ed.) Identifying Marine Phytoplankton. 1997. Eds. Academic Press, New York. 858 p.

Uthermöhl, H. 1958. Zur Vervollkommnung der quantitativen Phytoplankton Methodik. Mitt.int. Ver. theor. angew. Limnol. 9:1-38.

Villac, M.C.; Matos, M.G.; Santos, V.S.; Rodrigues, A.W. \& Viana, S.C. Composition and distribution of Pseudo-nitzschia from Guanabara Bay, Brazil: The role of salinity, based on field and culture observations. In: Steidinger, K.A.; Landsberg J.H; Tomas C.R. \& Vargo G.A. (eds). 2004. Harm. Alg. 2002. Florida, USA. 56-61 pp.
Villac, M.C. \& Tenenbaum, D.R. 2001. The coastal Pseudo-nitzschia from the state of Rio de Janeiro, Brazil. In: Hallegraeff, G. M.; Blackburn, S.I.; Bolch, C.J. \& Lewis R.J. (eds). Harmful Algal Bloom 2000. Tasmania, Australia. 34-37 pp.

Villac, M.C.; Noronha, V.A. de P.C. \& Pinto, T.de O. 2008. The phytoplankton biodiversity of the coast of the state of São Paulo, Brazil. Biota Neotrop. 8(3): 151-173.

Washington, H.G. 1984. Diversity, biotic and similarity indices. Water Res. 18: 653-694.

Witek, B. \& Plinski, M. 2000. The first recorded bloom of Prorocentrum minimum (Pavillard) Schiller in the coastal zone of the Gulf of Gdansk. Oceanologia 42: 29-36.

Submetido: Janeiro/2010 Revisado: Julho/2010 Aceito: Novembro/2010 